\title{
The Analysis of Spalling Effect on the Stress Distribution of Underground Pillar Spalling Using FLAC $^{3 D}$
}

\author{
Yichen Chen ${ }^{1 *}$, Yungchin Ding ${ }^{2}$ and Tinghan Feng ${ }^{3}$ \\ ${ }^{1}$ Institute of Mineral Resources Engineering, National Taipei University of Technology, Taiwan \\ ${ }^{2}$ Institute of Mineral Resources Engineering, National Taipei University of Technology, Taiwan \\ ${ }^{3}$ Institute of Mineral Resources Engineering, National Taipei University of Technology, Taiwan
}

*Corresponding author: Yichen Chen, Institute of Mineral Resources Engineering, National Taipei University of Technology, Taipei City, Taiwan.

Received Date: February 17, 2020

Published Date: February 20, 2020

\begin{abstract}
In underground mining, rib spalling is one of the early signs of elevated pillar stress, and which is characterized by fracture which intact rock is parallel to the direction of the maximum stress. Rib spalling causes the decrease of pillars, reduces the strength of pillar, and resulting in safety hazard to miners.

In this study, FLAC3D is utilized to simulate 8 models of different extent of rib spalling and different length of pillars. The results show that, in the case of the pillars without spalling, the maximum stress is concentrated on the four corners of top of pillar, followed by the center of top of pillar.

Keywords: Underground mining; FLAC3D; Pillar spalling; Pillar stress
\end{abstract}

\section{Introduction}

In underground mining, miners have to carry out high-risk work under extreme conditions [1]. Pillar and roof span stability are two essential prerequisites for safe working conditions in room-andpillar mines [2]. Unstable pillars can result in rock sloughing from the pillar and can lead to the collapse of the roof if one or more pillars should fail. Failure of the rock surrounding underground excavations in hard, brittle rock tends to initiate by a process of spalling in which slabs of rock are formed parallel to the excavation surfaces [2] (Figure 1). Spalling is a process that occurs when the confining stress is low and the rock splits in a direction parallel to the major compressive stress and forms slabs which can dislodge and fall [3]. In addition to causing safe hazards to operators, the rib spalling will also decrease the size of the pillar, reducing the pillar strength. In this study, a series of numerical models were created to simulate different size of pillars with spalling. Through the FLAC ${ }^{3 \mathrm{D}}$ models to understand the effect of sidewall spalling on the pillars by the stress distribution and diversification after simulation [4].

\section{Discussion}

Suppose the model in this study is assumed to be a single homogenous body. The model is divided into three layers, the top, the middle and the bottom layer. Each layer is 10 meters high, 90 meters wide, and the length are 96 meters and 105 meters for different size of pillar length. The pillars size is 10 meters high $\mathrm{X}$ width 10 meters $X$ each length 12 meters and 15 meters. The size of pillars and models are given in Table 1 . The sidewall spalling is 0 - 1 meter $、 2$ meters and 4 meters. Seven points are set on the side wall of the pillar to observe the stress change (Figure 2).

\section{The stress distribution of different pillar lengths}

Comparing Model NO.1 and Model N0.5 results (Figures $3 \& 4)$, as the length of the pillar increases, the stress of the pillar is dispersed better. As the length of pillar increases, the less stress is observed at point on the long edge of the pillar. The stress on the point $\mathrm{A} 4$ (/C4) is decreased $10 \%$ when pillar length is changed from 12 meters to 15 meters. 


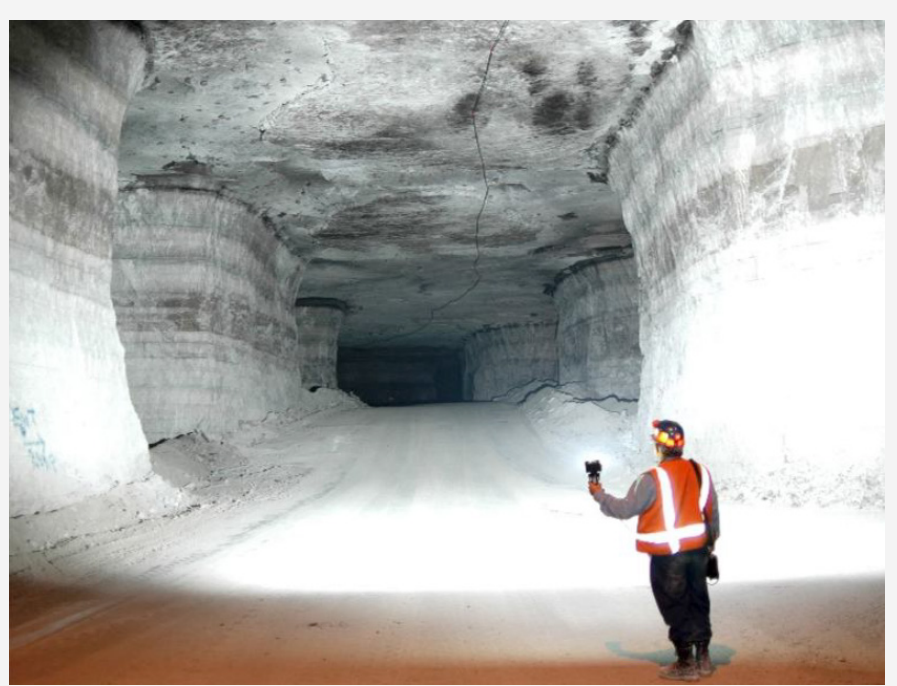

Figure 1: Stable pillars in a limestone mine at a depth of cover of $275 \mathrm{~m}$ (900 ft). Slightly concave pillar ribs formed as a result of minor spalling of the hard, brittle rock.

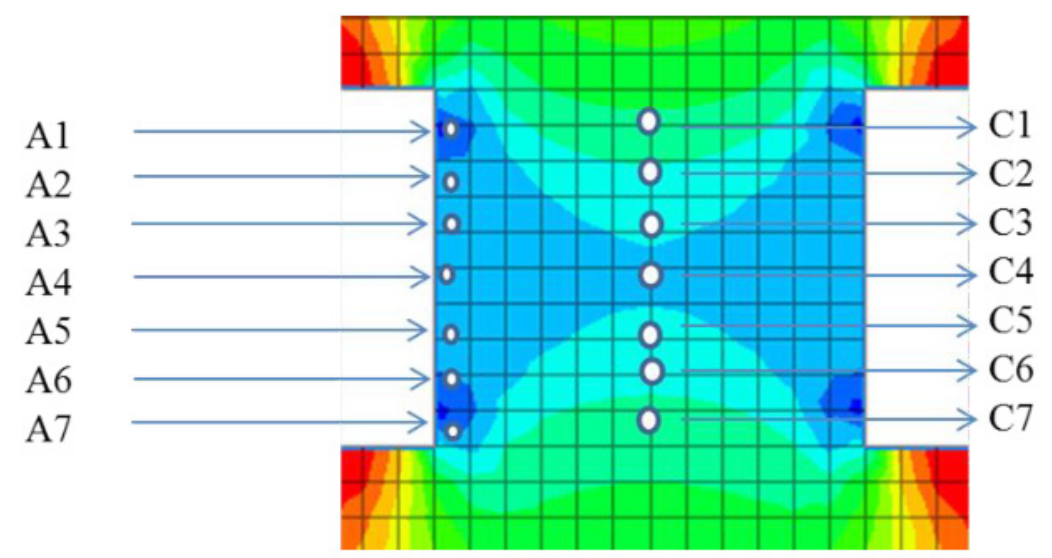

Figure 2: The points are set on the pillar to observe the stress results.

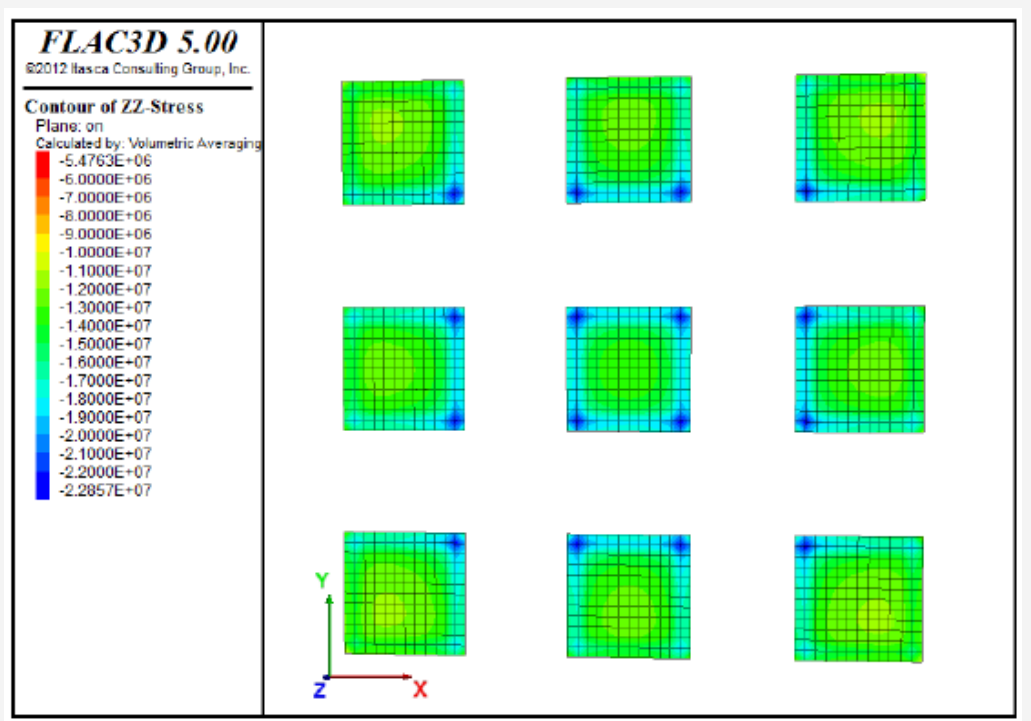

Figure 3: The roof of pillar's distribution of stress at cross section by model NO.1. 


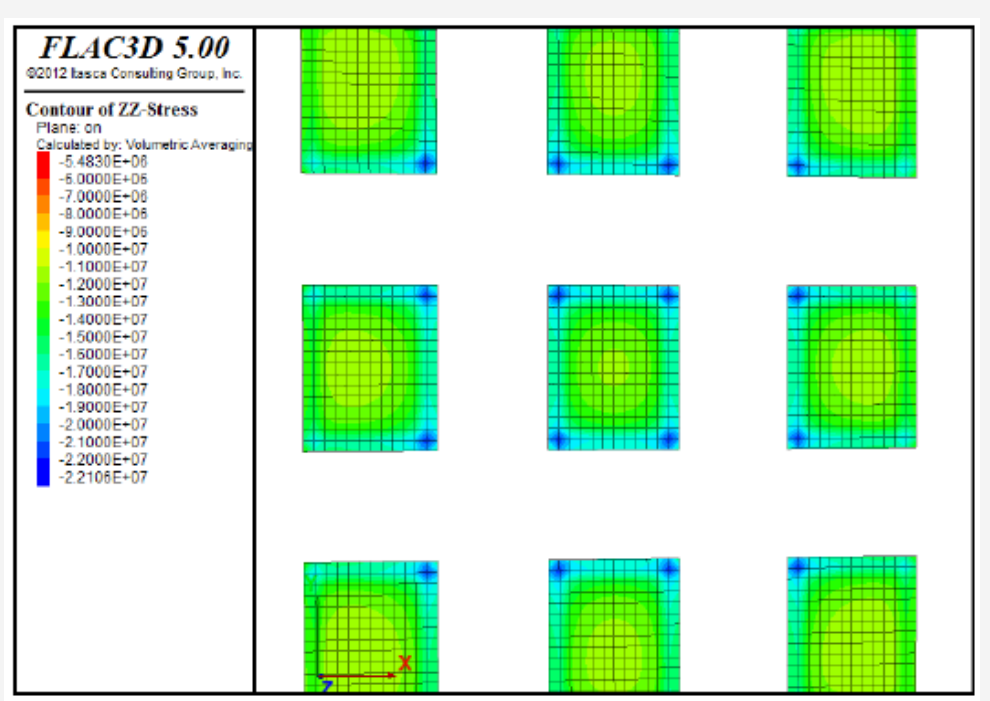

Figure 4: The roof of pillar's distribution of stress at cross section by model NO.5.

Table 1: The size of pillars and models.

\begin{tabular}{|c|c|c|c|c|c|c|c|c|}
\hline \multirow{2}{*}{$\begin{array}{l}\text { Model } \\
\text { No. }\end{array}$} & \multicolumn{3}{|c|}{ Models (m) } & \multicolumn{3}{|c|}{ Pillars (m) } & \multicolumn{2}{|c|}{ Spalling } \\
\hline & Length & Wide & High & Length & Wide & High & (m) & (\%) \\
\hline 1 & 96 & 90 & 30 & 12 & 10 & 10 & 0 & 0 \\
\hline 2 & 96 & 90 & 30 & 12 & 10 & 10 & 1 & 20 \\
\hline 3 & 96 & 90 & 30 & 12 & 10 & 10 & 2 & 40 \\
\hline 4 & 96 & 90 & 30 & 12 & 10 & 10 & 4 & 80 \\
\hline 5 & 105 & 90 & 30 & 15 & 10 & 10 & 0 & 0 \\
\hline 6 & 105 & 90 & 30 & 15 & 10 & 10 & 1 & 20 \\
\hline 7 & 105 & 90 & 30 & 15 & 10 & 10 & 2 & 40 \\
\hline 8 & 105 & 90 & 30 & 15 & 10 & 10 & 4 & 80 \\
\hline
\end{tabular}

\section{The stress distribution of different spalling proportion}

Rib spalling is one of the early signs of elevated pillar stress [2]. Assessment of the spalling mode of failure shows that extension fractures develop at low confinement, which can be seen as a cohesion weakening process [3-7]. In the spalling simulation, comparing Model NO.2 and Model N0.4 results (Figures 5\&6). As the sidewall spalling of the pillar increases, the distribution of the stress of the pillar is changed. The maximum stress shifts from the apex of the pillar to the center of the pillar. The spalling proportion seriously affects the stress of the pillars.

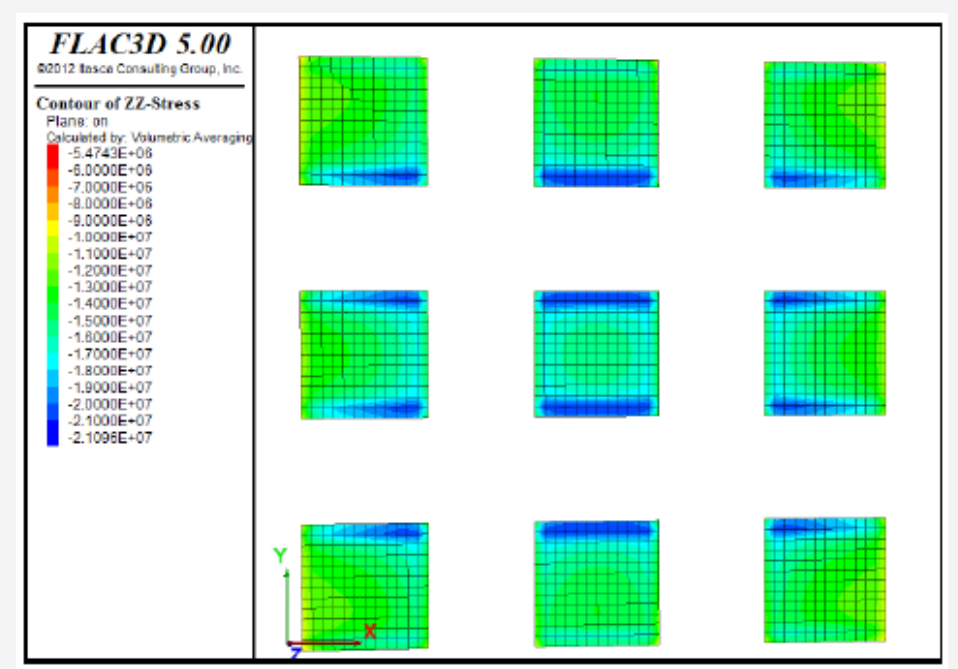

Figure 5: The roof of pillar's distribution of stress at cross section by model NO.2. 


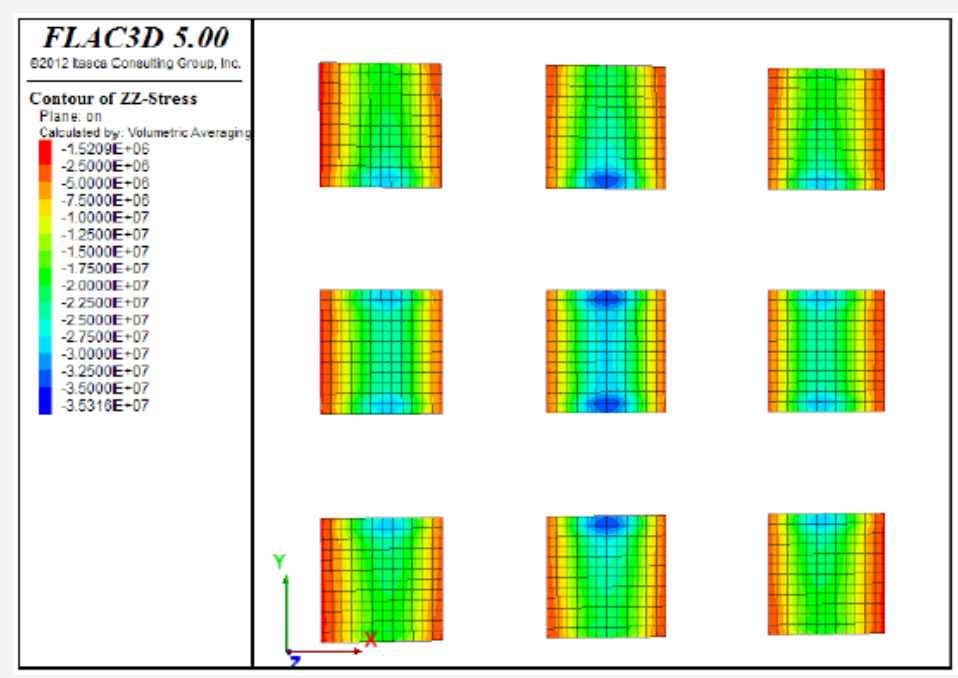

Figure 6: The roof of pillar's distribution of stress at cross section by model NO.4.

The stress on the point A4 (/C4) is increased $2 \%$ from nonspalling to 1 -meter spalling on the sidewall of pillar. Stress increases by $25 \%$ when it is increased to 2 meters, When increased to 4 meters, the stress is twice the stress of a non-spalling pillar.

At two-sided of the pillar (point A1, A2, A6, A7), the stress of the pillar does not change much. It can be estimated the spalling is the plane of weakness of the pillar. The stress concentrate on the plane of weakness, which in turn continuously cripple the plane of weakness, resulting in the failure of the pillar.

\section{Conclusion}

Under the conditions of different pillars length and sidewall spalling, the stress distribution of the pillar is analyzed by FLAC ${ }^{3 \mathrm{D}}$ modeling is available. According to the simulation, the stress and strength of the pillar could be reduced by increasing the pillar length. The longer the pillar, the better the stress reduction effect when the sidewall is spalling.

Shown in stress distribution from the results of the FLAC ${ }^{3 D}$ simulation, in the case of the complete and unreformed pillar, the maximum stress is concentrated in the four vertices of the pillar, and the center of the pillar is the secondary concentration of stress. However, as the sidewall spalling up, the maximum stress of will shift to the center of the sidewall of the pillar.

The above argument is corresponded with the previous studies, so it can be proved that the results of the FLAC $^{3 \mathrm{D}}$ simulation have its accuracy. Therefore, the simulation results of FLAC ${ }^{3 \mathrm{D}}$ can be used as the basis and prediction analysis of underground mining.

\section{Acknowledgement}

None.

\section{Conflict of Interest}

No conflict of interest.

\section{References}

1. Aiping Tan, Shoubin Wang, Ninh Xin, Yan Shi, Yuhuai Peng (2020) A Multi-Channel Transmission Scheme in Green Internet of Things for Underground Mining Safety Warning. IEEE Access 8775-788.

1. Gabriel S Esterhuizen, Dennis R Dolinar, John L Ellenberger, Leonard J Prosser (2011) Pillar and Roof Span Design Guidelines for Underground Stone Mines. (NIOSH) Department of Health and Human Services, Pittsburgh, PA, WA, USA, pp. 64.

2. TR Stacey (1987) A simple extension strain criterion for fracture of brittle rock. International Journal of Rock Mechanics and Mining Sciences \& Geomechanics Abstracts 18(6): 469-474.

3. Ting Han Feng, Yung Chin Ding (2019) The Analysis of Spalling effect on the Stress Distribution of Underground Pillar Spalling Using FLAC ${ }^{3 D}$.

4. CD Martin, NA Chandler (1994) The progressive fracture of Lac du Bonnet granite. International Journal of Rock Mechanics and Mining Sciences \& Geomechanics Abstracts 31(6): 643-659.

5. Diederichs MS, Coulson A, Falmagne V, Rizkalla N, Simser B (2002) Application of rock damage limits to pillar analysis at Brunswick Mine. Proceedings of NARMS-TAC, Toronto, Ontario, Canada.

6. Hajiabdolmajid V, Martin CD, Kaiser PK (2000) Modelling brittle failure of rock. International Journal of Rock Mechanics and Mining Sciences 39(6): 731-741. 